\title{
Hand, foot and mouth disease as an emerging public health problem: Case report of familial child-to-adult transmission
}

\section{Choroba dłoni, stóp i jamy ustnej jako pojawiający się problem dla zdrowia publicznego - opis przypadku rodzinnego przeniesienia zakażenia z dziecka na dorosłego}

\author{
Zuzanna Ślebioda ${ }^{A-D}$, Barbara Dorocka-Bobkowska ${ }^{\mathrm{A}, \mathrm{E}, \mathrm{F}}$ \\ Department of Gerodontology and Oral Pathology, Poznan University of Medical Sciences, Poland \\ A - research concept and design; $\mathrm{B}$ - collection and/or assembly of data; $\mathrm{C}$ - data analysis and interpretation; \\ $D$ - writing the article; $E$ - critical revision of the article; $F$ - final approval of the article
}

Address for correspondence

Zuzanna Ślebioda

E-mail: zuzia_slebioda@02.pl

Funding sources

None declared

Conflict of interest

None declared

Received on November 8, 2017

Reviewed on November 26, 2017

Accepted on December 5, 2017

\begin{abstract}
Hand, foot and mouth disease (HFMD) is a highly contagious viral infectious disease that commonly affects small children. Typical clinical symptoms include low-grade fever, malaise and myalgia followed by a characteristic maculovesicular eruption on hands, feet and the oral cavity. In most cases, the disease is self-limiting, but some severe complications, including pneumonia, meningitis and encephalitis, may occasionally occur. The most severe outbreaks of HFMD have been observed in Asia-Pacific region; however, epidemics in Europe and America have also occurred in the past. The disease is caused by an infection with various members of Picornaviridae family in the genus enterovirus, most commonly by Coxsackievirus A6 (CVA6), Coxsackievirus A16 (CVA16), and Enterovirus 71 (EV71).

This report describes the intra-familial transmission of hand, foot and mouth disease between 2 sibling children (a 3-year-old girl and a 5-year-old boy) and their immunocompetent mother in Poland. Clinical presentation with signs, symptoms and a suggested treatment regime are discussed and illustrated.
\end{abstract}

Key words: oral mucosa, hand, foot and mouth disease, enteroviruses, Coxsackie A virus

Słowa kluczowe: błona śluzowa jamy ustnej, choroba dłoni, stóp i jamy ustnej, enterowirusy, wirus Coxsackie A

D0I

$10.17219 / \mathrm{dmp} / 80995$

Copyright

○ 2018 by Wroclaw Medical University

and Polish Dental Society

This is an article distributed under the terms of the

Creative Commons Attribution Non-Commercial License

(http://creativecommons.org/licenses/by-nc-nd/4.0/) 


\section{Introduction}

Hand, foot and mouth disease (HFMD) is a common childhood illness most typically seen in children younger than 10 years of age and is characterized by fever, malaise and maculovesicular eruptions located mainly on the hands, feet and in the mouth, and less often on the buttocks. In some cases, nail matrix arrest may be affected. ${ }^{1-3}$ However, the disease is usually self-limiting and complications such as pneumonia, aseptic meningitis, acute flaccid paralysis or brainstem encephalitis rarely occur. ${ }^{1,2,4,5}$

The disease is caused by an infection with various members of the Picornaviridae family in the genus enterovirus; most commonly by Coxsackievirus A6 (CVA6), Coxsackievirus A16 (CVA16) and Enterovirus 71 (EV71). These are small, non-enveloped viruses that consist of a single-stranded, positive-sense RNA. Over 110 genetically distinct enteroviruses responsible for infections in humans and nonhuman primates have been recognized. ${ }^{4,6}$ Humans are the only known reservoir of the disease. Enteroviruses spread via fecal-oral, oral-oral and respiratory routes. The basic mode of transmission is the intra-familial path. ${ }^{1}$ The incubation period ranges from 3 to 6 days; however, the virus can be shed in the stool and saliva for several weeks after the onset of the primary signs of the infection. ${ }^{4}$

HFMD was identified as an enterovirus infection in the late $1950 \mathrm{~s} .{ }^{4,6}$ Outbreaks of the disease have been mainly due to 2 types of Enterovirus A species: CVA16 and EV71.7,8 A series of EV-A71 epidemics was observed in the Asia-Pacific region between 1997 and 2010, while the recent outbreaks of severe HFMD in the United States were caused by CVA6, as in Finland. ${ }^{6,7}$ Certain symptoms are associated with each of the 2 virus infections: CVA6 causes nail shedding during the convalescence period, while CVA16 leads to the formation of large, vesicular eruptions. ${ }^{4}$

Enterovirus infections remain an important public health problem, mainly due to the HFMD-associated complications during epidemics. Currently, there is no causative treatment or effective vaccinations available; however, several vaccines are being investigated for the HFMD

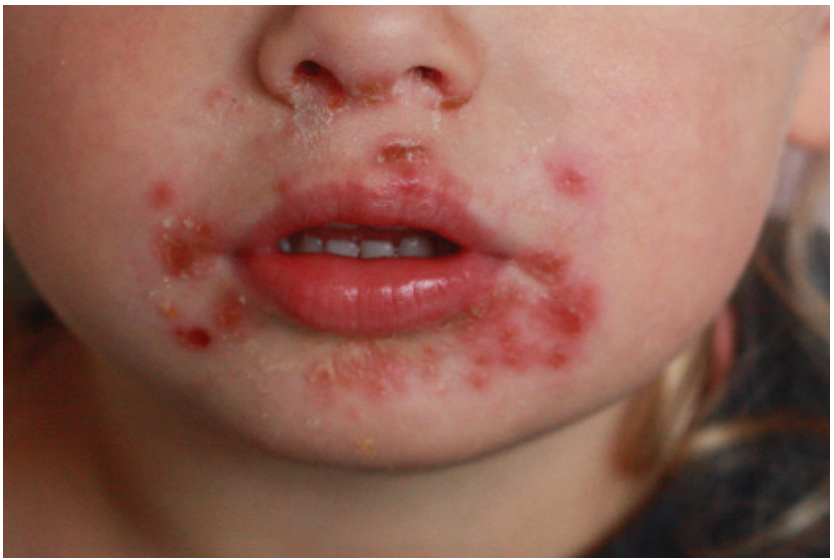

Fig. 1. Maculovesicular eruptions with crusts in the perioral area of a 3-year-old female patient application. ${ }^{4,6}$ Due to the high infectivity, the restrictive hygienic procedures in limiting interpersonal spread and isolation of symptomatic cases are essential in preventing HFMD transmission and controlling the outbreaks. ${ }^{9}$

In this paper, we present a case of intra-familial transmission of hand, foot and mouth disease between 2 children attending kindergarten and their generally healthy adult relative in Poland. Prodromal signs, clinical presentation, diagnostics, prophylaxis, and treatment options are also discussed.

\section{Case report}

A 3-year-old female child attended the oral pathology office due to maculovesicular skin eruptions affecting perioral region, accompanied by a sore throat and moderately severe discomfort while consuming sweet and acidic food and beverages. These symptoms were preceded by a mild fever and fatigue, which had appeared 2 days before the development of skin and mucosal lesions.

Despite the illness, the child was considered generally healthy. No allergies or nutritional intolerances were reported by the child's parents. The patient had not traveled abroad in the past year, but she had started to attend a kindergarten 2 weeks before.

Informed consent was obtained from the parent as a part of the routine protocol prior to the clinical examination. On examination, red macules, papules and vesicles where revealed in the perioral area, on the hands, the soles of the feet, and buttocks. The lesions where not itchy and moderate discomfort appeared only in the oral area (Fig. 1, 2). During the intraoral examination, the redness of the palatal arches and moderately coated tongue were observed with no other pathologic eruptions being evident.

Based on the characteristic presentation and localization of the lesions on hands, feet, buttocks, and oral region with no other area of the body involved, the diagnosis of hand, foot and mouth disease was established. Meanwhile, the staff of the kindergarten informed the parents of another case of HMFD in the facility.

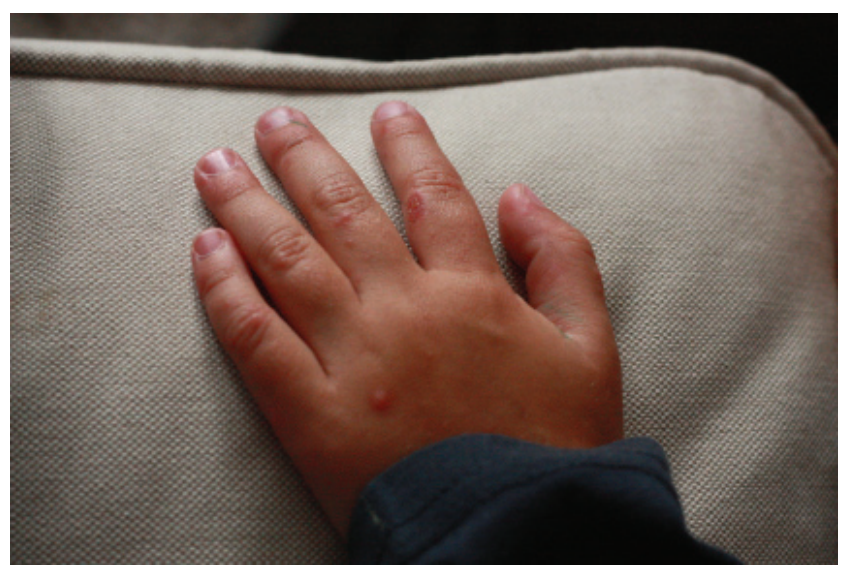

Fig. 2. Maculopapular lesions on a hand of a 3-year-old female patient 
About 2 days after the development of skin lesions in this 3-year-old girl, a fever accompanied by a sore throat appeared in her 5-year-old brother. These symptoms where followed by single reddish macules present on the plantar hand surfaces and the soles of the feet. Maculovesicular eruptions appeared also on his buttocks. The boy reported a transient tenderness of the palms and soles. No lesions developed in the perioral area, while intraorally, redness and edema, accompanied by a single vesicular eruption on the labial mucosa were observed (Fig. 3).

Like his sister, the boy was considered generally healthy without any relevant medical history. He had not visited any foreign countries in the past year, but he was attending the same kindergarten as his younger sister. Although, due to the absence of the perioral lesions, the clinical presentation in the boy was not as evident as in his sister, based on the symptoms and the history, a diagnosis of hand, feet and mouth diseases was made.

In both children, the acute symptoms of HFMD lasted for approx. 7 days and passed without any complications. Exfoliation on the palms and soles appeared during the healing stage of the infection. This sign was evident in the boy and insignificantly marked in his sister (Fig. 4, 5).

The evaluation of the full blood count, anti-streptolysin $\mathrm{O}$ (ASO) and C-reactive protein (CRP) levels performed on the 5-year-old boy 2 weeks after the primary signs of the infection did not show any abnormalities. Also, no pathologies were revealed in the urinalysis.

Approximately 5 weeks after the acute phase of the disease, onychomadesis appeared in both children (Fig. 6).

At the same time when the boy started to suffer the prodromal signs of the HFMD, flu-like symptoms, including malaise, fever, muscle pain, and sore throat, also appeared in the children's mother. It was followed by a very limited reddish rash on the palms and soles with no other pathologic findings. Simultaneously, she reported tenderness of the hands and feet. All the symptoms subsided within 3-4 days. The female was generally healthy; she did not report any complaints and was not using any dental appliances. Considering the history of HFMD in her children and based on very discrete, but rather characteristic clinical symptoms, this female patient was also diagnosed with HFMD.

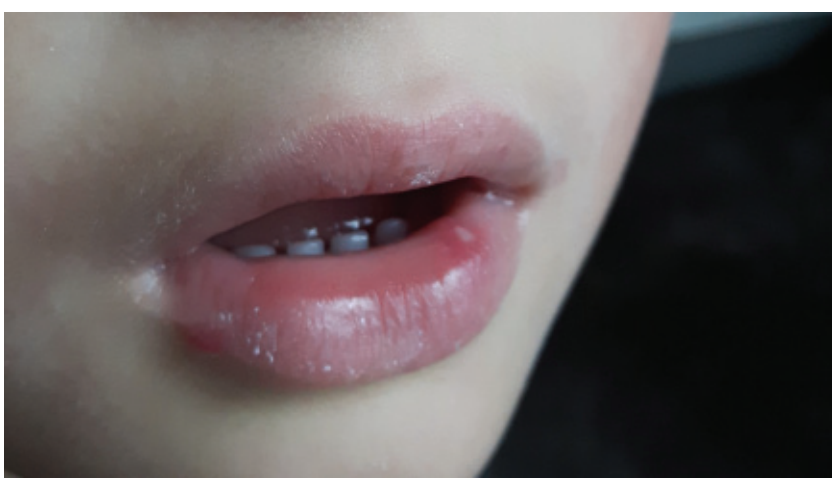

Fig. 3. A vesicular eruption on the lower lip of a 5-year-old male patient

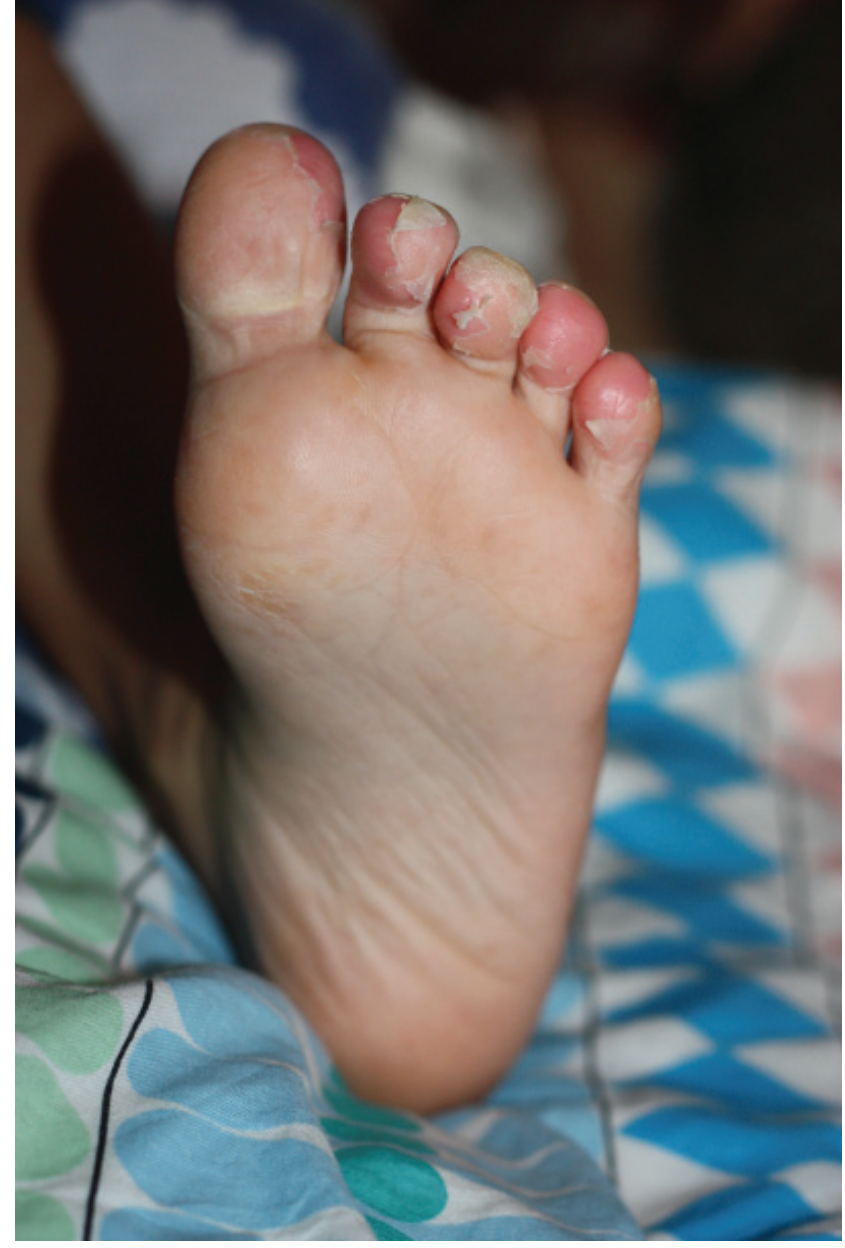

Fig. 4. Exfoliation of soles in a 5-year-old male patient

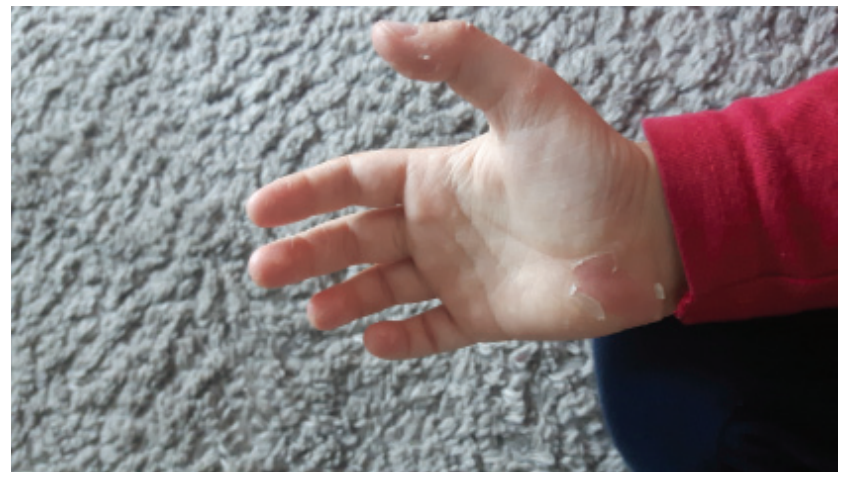

Fig. 5. Exfoliation of palms in a 5-year-old male patient

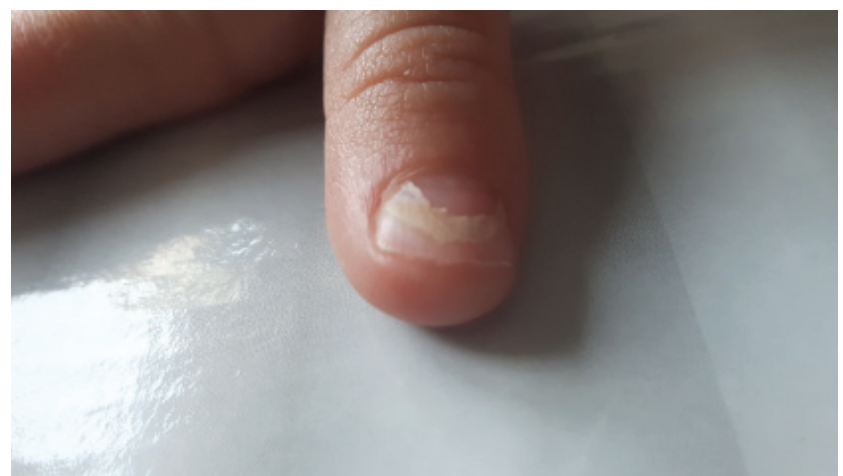

Fig. 6. Onychomadesis on the right thumb with visible Beau's line in 3-year-old female patient 
No specific treatment was induced in the members of this family, apart from antipyretic drug containing paracetamol prescribed for the boy patient during the $1^{\text {st }}$ day of the infection. Due to the high infectivity of the disease, a disinfecting mouth rinse and a restrictive hygienic regime was recommended.

\section{Discussion}

Greater exposure to microbial vectors due to changing travel habits and lifestyles, occupational migration, military conflicts, and climate changes, which has occurred in recent times, leads to an increasing frequency of infections caused by new or old, re-emerging viruses. The recurrences of known pathogens and the evolution of additional new variants should be considered. HFMD predominantly affects infants and small children. As a highly contagious disease, it spreads rapidly in childcare facilities and among family members. Although normally the course of the disease is not very dramatic, the morbidity and mortality associated with the recent enterovirus outbreaks has demonstrated the urgent need for effective antiviral treatment and for more education regarding the disease prophylaxis. ${ }^{1,6,9}$

The case series in this paper has demonstrated that HFMD affects not only children or immunocompromised subjects, but in favorable conditions may easily spread to a generally healthy adult person. According to some reports, approx. $11 \%$ of adults become infected after the exposition to the pathogen, although less than $1 \%$ of those develop the HFMD clinical symptoms. ${ }^{10,11}$ Cases of immunocompetent adults suffering from HFMD have also been described by other authors. ${ }^{10-16}$ Familial transmission between the child and an adult, similar to the situation observed in our case, was presented in 3 case series by Kaminska et al. ${ }^{12}$ Viral transmission occurred faster between the infected pediatric patient and an adult than between 2 adults. Intra-familial transmission between a small child and immunocompetent adults was also the subject of case reports by Omaña-Cepeda et al. and Tai et al. ${ }^{13,14}$ An unusual location of erythematous crusted macules on the scalp, which accompanied a typical spectrum of clinical symptoms in a generally healthy adult, was presented by Andreoni and Colton. ${ }^{15}$ In that case, a resolution of oral and cutaneous eruptions was followed by onychomadesis. Regrowth of new fingernails appeared approx. 2 months post infection. A total of 5 adult cases of CVA16-confirmed HFMD with similar disease progression were presented by RamirezFort et al. ${ }^{10}$ In all the subjects, the prodromal symptoms were followed by the development of rash on the palms and soles, and to a lesser degree on the facial skin and the buttocks. The cutaneous lesions evolved from macules to vesicles, followed by erosions. The subsequent desquamation was than observed. The authors emphasized that erythematous or pruritic macular lesions in HFMD may mimic those of secondary syphilis. No systemic complications, e.g., encephalitis or myocarditis, where observed in those patients. Meanwhile, in an adult case study of HFMD presented by Flor de Lima et al., typical oro-cutaneous eruptions were followed by the development of myopericarditis, rarely described as a complication of this condition. ${ }^{16}$

In most cases, HFMD in adults can be easily diagnosed based on clinical grounds and the patient's history. In differential diagnosis, several conditions must be considered, including varicella zoster, papular urticaria, impetigo, or syphilis. ${ }^{10,17}$ In doubtful cases, rapid molecular diagnostic methods should be utilized to recognize an enteroviral disease. ${ }^{5}$ Histopathologic findings, which typically include intense edema, necrotic or shadow keratinocytes, and neutrophilic exocytosis with T-cell infiltrate, may assist the diagnosis. ${ }^{18}$ Currently, there is neither an effective antiviral therapy, nor an effective vaccine available for the disease. Supportive care, including maintenance of hydration and pain control, together with antipyretics and optionally antihistamines to reduce itching, are recommended for the management of patients with HFMD. ${ }^{1,4,6}$

It needs to be emphasized that the disease is very contagious and has the potential to spread very quickly through a large population. To avoid major outbreaks, containment of the disease once it is diagnosed is required. Strict implementation of basic protocols like monitoring cleanliness of the hands, utensils and drinking water, together with preventing affected children from attending school and other childcare facilities is recommended. 2,4,9

\section{References}

1. Ventarola D, Bordone L, Silverberg N. Update on hand-foot-andmouth disease. Clin Dermatol. 2015;33:340-346.

2. Scully $C$, Samaranayake LP. Emerging and changing viral diseases in the new millennium Oral Dis. 2016;22:171-179.

3. Cuppari C, Manti S, Arrigo T, Salpietro C. Not only fever and palmoplantar vesicular eruption. Infect. 2014;42:947-948.

4. Aswathyraj S, Arunkumar G, Alidjinou EK, Hober D. Hand, foot and mouth disease (HFMD): Emerging epidemiology and the need for a vaccine strategy. Med Microbiol Immunol. 2016;205:397-407.

5. Zhang D, Li R, Zhang W, et al. A case-control study on risk factors for severe hand, foot and mouth disease. Sci Rep. 2017;13:40282.

6. Lugo D, Krogstad P. Enteroviruses in the early 21st century: New manifestations and challenges. Curr Opin Pediatr. 2016;28:107-113.

7. Osterback R, Vuorinen T, Linna M, Susi P, Hyypiä T, Waris M. Coxsackievirus A6 and hand, foot, and mouth disease, Finland. Emerg Infect Dis. 2009;15:1485-1488.

8. Koh WM, Bogich T, Siegel K, et al. The epidemiology of hand, foot and mouth disease in Asia: A systematic review and analysis. Pediatr Infect Dis J. 2016;35:e285-300.

9. Chan JHY, Law CK, Hamblion E, Fung H, Rudge J. Best practices to prevent transmission and control outbreaks of hand, foot, and mouth disease in childcare facilities: A systematic review. Hong Kong Med J. 2017;23:177-190.

10. Ramirez-Fort MK, Downing C, Doan HQ, et al. Coxsackievirus A6 associated hand, foot and mouth disease in adults: Clinical presentation and review of the literature. J Clin Virol. 2014;60:381-386.

11. Chiu WY, Lo YH, Yeh TC. Coxsackievirus associated hand, foot and mouth disease in an adult. QJM. 2016;109:823-824. 
12. Kaminska K, Martinetti G, Lucchini R, Kayac G, Mainettia C. Coxsackievirus $A 6$ and hand, foot and mouth disease: Three case reports of familial child-to-immunocompetent adult transmission and a literature review. Case Rep Dermatol. 2013;5:203-209.

13. Omaña-Cepeda C, Martínez-Valverde A, Sabater-Recolons M, JanéSalas E, Marí-Roig A, López-López J. A literature review and case report of hand, foot and mouth disease in an immunocompetent adult. BMC Res Notes. 2016;9:165. doi: 10.1186/s13104-016-1973-y.

14. Tai WC, Hsieh HJ, Wu MT. Hand, foot and mouth disease in a healthy adult caused by intrafamilial transmission of enterovirus $71 . \mathrm{Br} J$ Dermatol. 2009;160:890-892.

15. Andreoni AR, Colton AS. Coxsackievirus B5 associated with hand-foot-mouth disease in a healthy adult. JAAD Case Rep. 2017;27:165-168.

16. Flor de Lima B, Silva J, Rodrigues AC, Grilo A, Riso N, Vaz Riscado M. Hand, foot, and mouth syndrome in an immunocompetent adult: A case report. BMC Res Notes. 2013;6:441.

17. Kashyap RR, Kashyap RS. Hand, foot and mouth disease: A short case report. J Clin Exp Dent. 2015;7:e336-338.

18. Second J, Velter C, Calès S, Truchetet F, Lipsker D, Cribier B. Clinicopathologic analysis of atypical hand, foot, and mouth disease in adult patients. J Am Acad Dermatol. 2017;76:722-729. 
